\title{
Algorithm of optimization of production of entomophages on the criterion of quality
}

\author{
V. Lysenko, \\ Doctor of technical sciences, \\ National University of life and environmental sciences of Ukraine \\ I. Chernova \\ Engineering and technological Institute "Biotechnics" NAAS of Ukraine
}

The purpose. To develop algorithm of security of the set quality of production of entomophages on the basis of utilization of illegible logic. Methods. Illegible logic, E. Harrington's theory. Results. Algorithm is developed of optimization of production of entomophages on the criterion of quality on an instance of entomological specimen Brakon (Habrobracon hebetor). Input data for optimization were values of biological and complex indices gained at different parameters of microclimate. Levels of desirability of complex merit number of entomophage Brakon are specified by means of E. Harrington's function. Criterion of optimization of production of entomophages is the degree of approximation of desirability of complex merit number to linguistic assessment "very good". The illegible assessment of desirability of complex merit number of entomophage Brakon is carried out. The mean error of approximating is in acceptance limits. Conclusions. On the basis of the theory of illegible logic the algorithm of optimization of production of entomophages on a criterion of performance is developed. Entomologic products with merit number "very good" match the following parameters of microclimate: air temperature $26-29^{\circ} \mathrm{C}$, relative humidity of air $70-80 \%$. These parameters of microclimate can be used at formation of strategies of control by conforming system of automation.

Key words: production of entomophages, optimization, quality, E. Harrington's function of desirability, illegible logic.

The issue of optimization of entomological productions for today is relevant due to the need to obtain the maximum amount of entomoproducts of guaranteed quality at minimum energy costs in its production. The direction of research on the optimization of the production of entomophages relates to:

- transition to natural feed substitutes; refusal of vegetative plants; selection of technological substrates for collecting eggs and puppets of entomophages [1];

- rational relationship parasite-host;

- creation of favorable conditions for growing insects [2];

- optimization of feed [3, 4];

- quality control of the production process [5];

- preservation of the minimum level of diversity and functional stability of artificial populations [2, 6, 7];

- development of energyefficient control systems for entomophages quality [8];

- the use of intellectual technologies, in particular, the optimization of the nutrient medium based on the use of genetic algorithm [9].

The purpose. Develop an algorithm to ensure the specified quality of production entomophages on the basis of the use of fuzzy logic.

Materials and methods of research. The object of research is the production of entomophage Habrobracon hebetor. The materials used were the results of experimental studies obtained by the scientists of the Engineering Technology Institute "Biotechnics" on the results of the research work № 35.00.01.05П «Develop technological support cultivation uterine culture of Habrobracon hebetor». Methods of research - fuzzy logic, Harrington theory. 
Results of research. The feature of modern technologies of mass development of entomophages is the preassigned output of the final product of high quality per unit of production space [10].

The quality of entomophages in technocenosis is estimated according to biological indices (fertility of females, the emergence of imago, sex index, number of deformed individuals, etc.) and depends on the accuracy of maintaining the temperature and relative humidity of air in the zone of their development [8].

The algorithm of optimization of production of entomophages by quality criteria (fig.1) is developed on the example of the entomologic drug Habrobracon hebetor. The initial data for optimization were the values of biological quality indices ( $P 1$ - number of females, \%; $P_{2}$ - the number of imago received from one female, pcs; $\mathrm{P}_{2}$ - the number of infected caterpillars of Ephestia kuehniella, \%) obtained with different parameters of the microclimate. Experiments from Habrobracon hebetor, which was bred in Petri dishes, were carried out in a thermostat, where the air temperature varied in the range (17-29) oC, and the relative humidity was $(60-80) \%$. Petri dishes, glass tubes, hand magnifiers, medical tweezers, biological microscopes, thermostats, weights for weighing eggs are used to determine the quality of entomocultures [11].

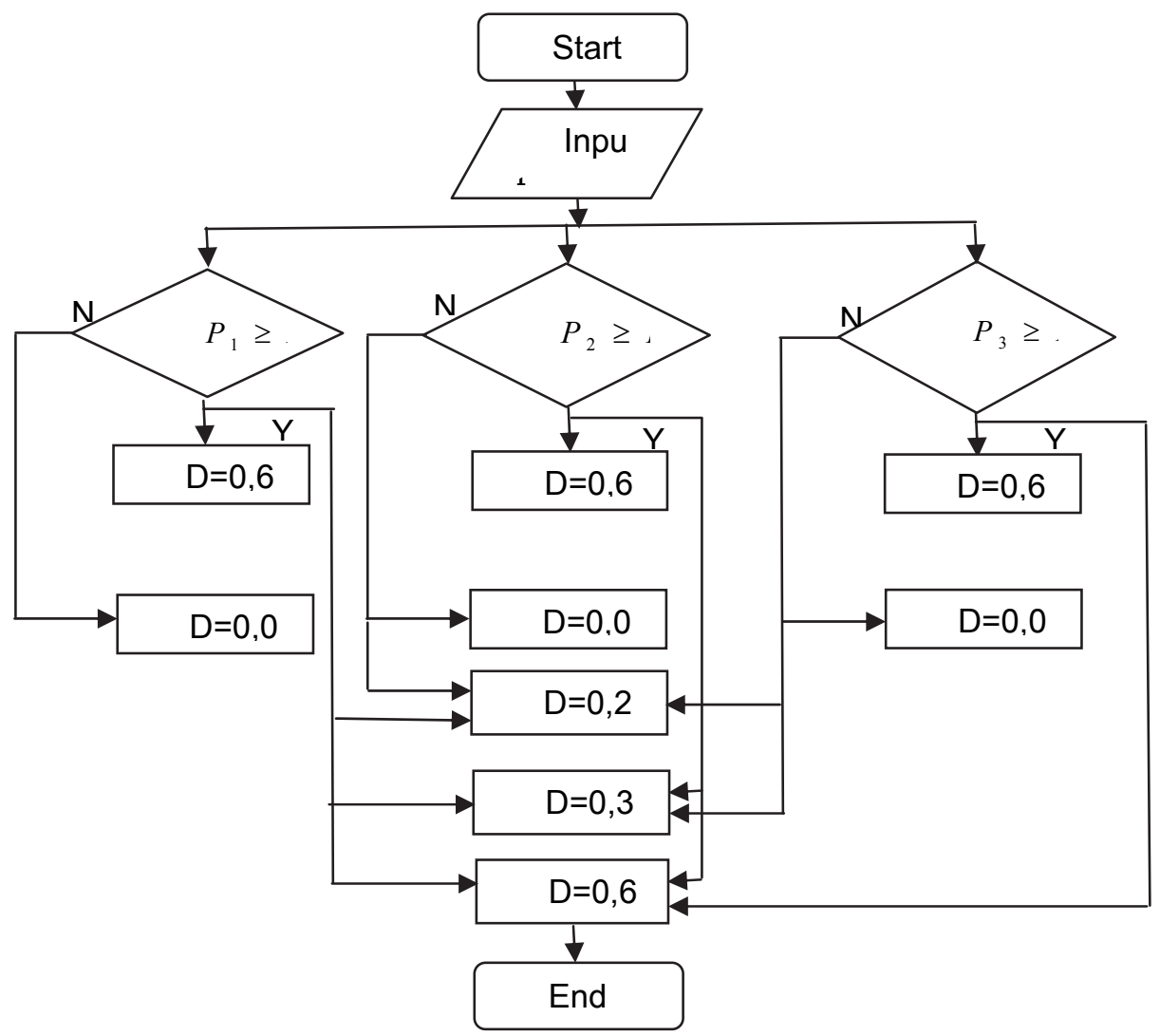

Fig.1 Algorithm of optimization of production of entomophages

Complex index of entomocultural quality due to heterogeneity of biological indicators is calculated according to the expression [12]:

$$
\mathrm{K}=\sqrt[n]{\prod_{j=1}^{n} \frac{P_{j}}{P_{j}^{\sigma}}},
$$

where $P_{j}$ - the absolute value $j$-th of the biological quality index of entomocultures; $P_{j}{ }^{6}$ - its basic value; $\mathrm{n}$ - number of indicators. 
The basic values of the quality indicators of Habrobracon hebetor are: $P_{1}^{\sigma}$ - not less than $45 \%, P_{2}^{\sigma}$ not less than 20 pieces, $P_{3}^{\sigma}$ - not less than $40 \%$ [11].

To establish the correspondence between the values of complex indicators of the quality of the entomophage under various microclimate parameters and their desirability, we use the Harrington function $D[13]$ :

$$
D=\exp (-\exp (-K))
$$

The criterion for optimizing the production of entomophages is the proximity of the desirability of a complex quality index to a linguistic assessment "very good" in accordance with the Harrington desirable scale (Table 1), that is, the objective function has the form:

$$
D \rightarrow(0,08 \ldots 1,0) \text {. }
$$

\section{Standard marks on the scale of desirability E. Harrington [14]}

\begin{tabular}{|l|c|}
\hline Desirability & $\begin{array}{c}\text { Marks on the scale of } \\
\text { desirability }\end{array}$ \\
\hline Very good & $1,00-0,80$ \\
Good & $0,80-0,63$ \\
Satisfactory & $0,63-0,37$ \\
Bad & $0,37-0,20$ \\
Very bad & $0,20-0,00$ \\
\hline
\end{tabular}

The levels of desirability of the complex indicator of the quality of the entomophage Habrobracon hebetor are determined depending on the degree of proximity of the indicators (number of females and imago from one female, infected caterpillars Ephestia kuehniella) to the baseline values for different parameters of the microclimate (Table 2).

\section{Levels of desirability of a complex index of entomophage quality Habrobracon hebetor}

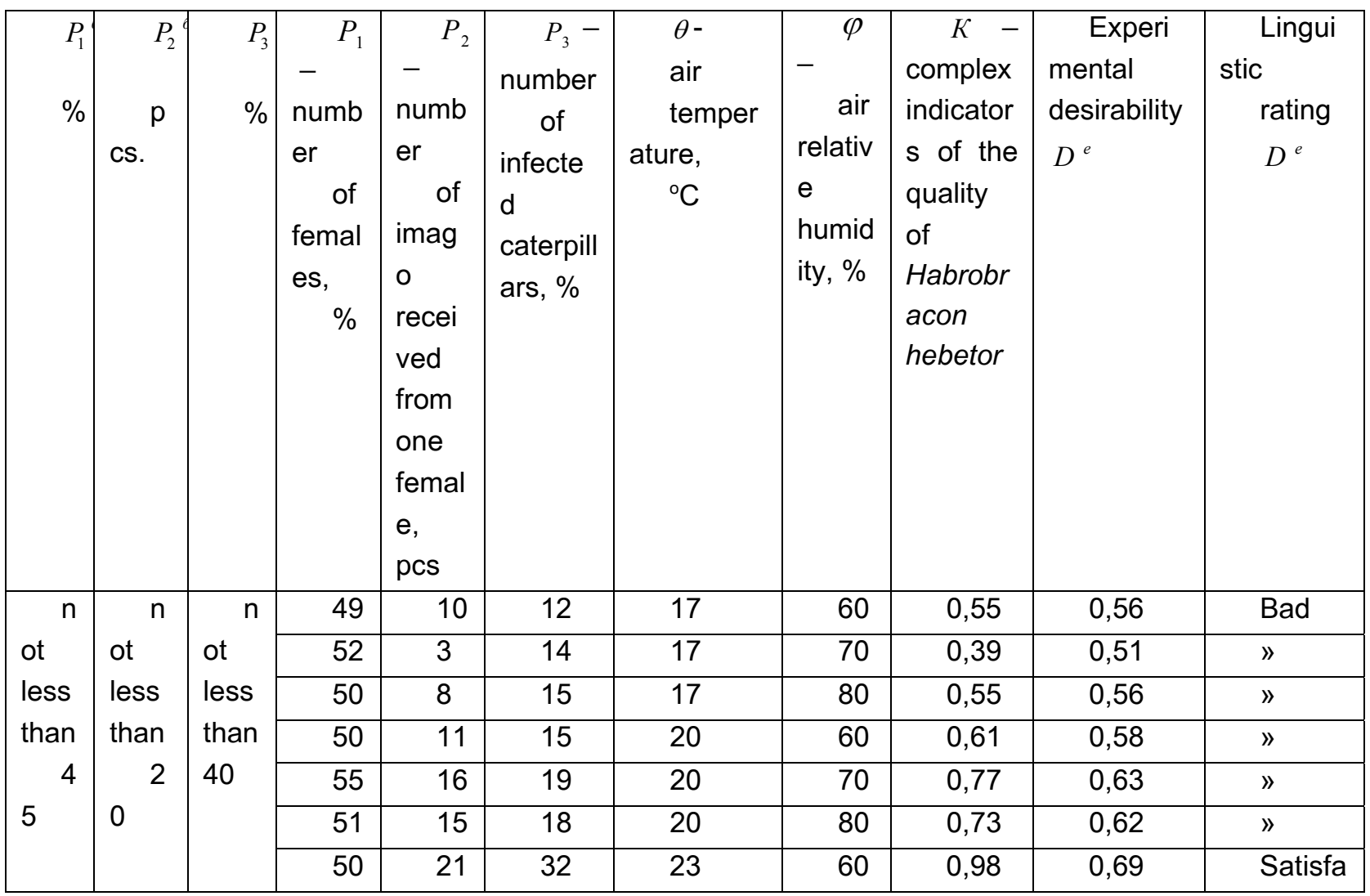




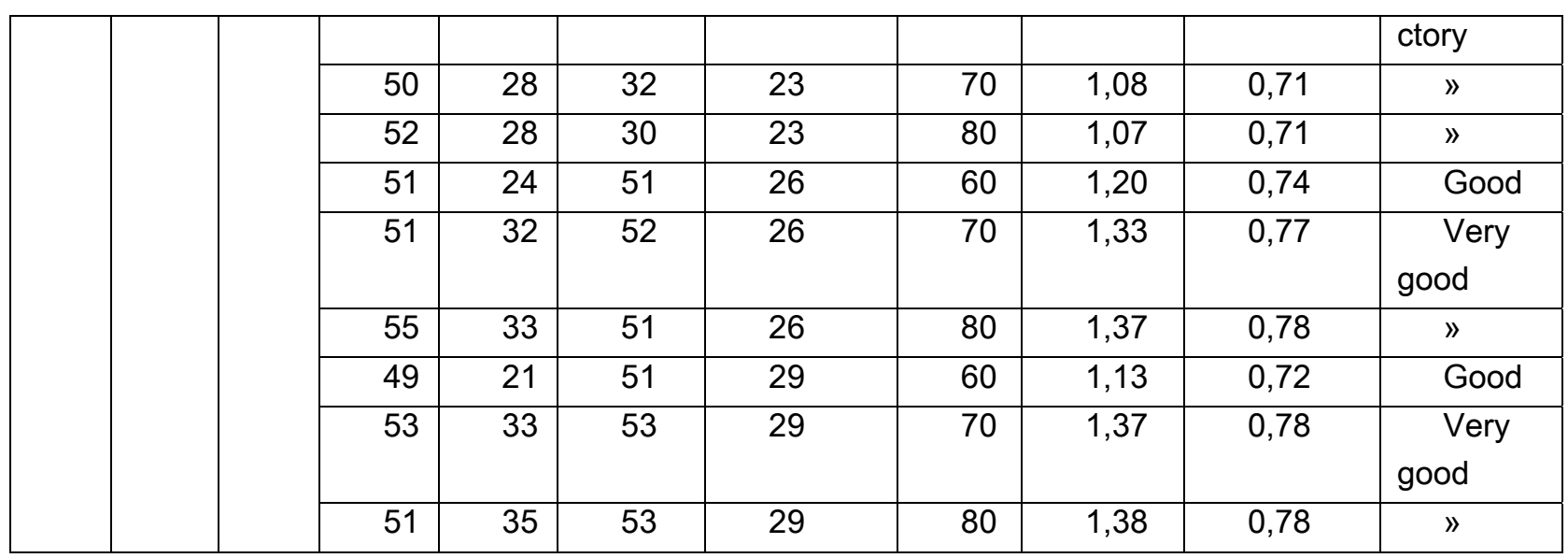

As can be seen from table. 2 experimental studies were carried out at limited air temperature values: there are no data on the quality of entomocultures at a temperature of $18^{\circ} \mathrm{C}, 19^{\circ} \mathrm{C}, 21^{\circ} \mathrm{C}, 22^{\circ} \mathrm{C}, 27^{\circ} \mathrm{C}$, $28^{\circ} \mathrm{C}$ (it is not always possible to carry out an experimental assessment of the degree of influence of the factors). The peculiarity of the biological object is the in its various behavior under the influence of a significant number of factors of influence (abiotic, biotic, technological). In order to assess the influence of these factors on the quality of the products produced, it is possible, from our point of view, to apply the theory of fuzzy logic, which is based on the use of knowledge about the object of research, presented in the form of rules of the type «if - then». Fuzzy logic, belonging to one of the modern intellectual technologies, can also be used to develop a model of optimal process control [15].

For a fuzzy assessment of the desirability of a complex index of the quality of the entomophage Habrobracon hebetor, the Fuzzy Logic Toolbox Matlab expansion package and the Mamdani type fuzzy output system [16] were used.

As a result of the desirable levels of a complex quality index of the entomophage Habrobracon hebetor a fuzzy knowledge base was created which contains data (Table 3) and rules (Table 4).

\section{Data to create a knowledge base}

\begin{tabular}{|c|c|c|c|c|c|}
\hline $\begin{array}{l}\quad \text { Input } \\
\text { and } \\
\text { output } \\
\text { variables } \\
\text { paramet } \\
\text { ers }\end{array}$ & \begin{tabular}{l}
\multicolumn{2}{c}{ Input and } \\
range of \\
output \\
parameters
\end{tabular} & $\begin{array}{l}\text { Term } \\
\text { sets }\end{array}$ & $\begin{array}{l}\text { Linguistic } \\
\text { assessment } \\
\text { parameters }\end{array}$ & of & $\begin{array}{l}\text { The type and } \\
\text { parameters } \\
\text { membership } \\
\text { function }\end{array}$ \\
\hline \multirow[t]{3}{*}{$\mathrm{T},{ }^{\circ} \mathrm{C}$} & \multirow[t]{3}{*}{$17-29$} & T1 & \multicolumn{2}{|c|}{ Low temperature } & Gaussmf $[2,038 ; 17]$ \\
\hline & & T2 & Average & 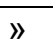 & Gaussmf $[2,038 ; 23]$ \\
\hline & & T3 & High & 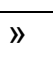 & Gaussmf $[2,038 ; 29]$ \\
\hline \multirow[t]{3}{*}{$\mathrm{W}, \%$} & \multirow[t]{3}{*}{$60-80$} & W1 & Low humidity & & Gaussmf $[3,397 ; 60]$ \\
\hline & & W2 & Average & 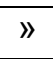 & Gaussmf $[3,397 ; 70]$ \\
\hline & & W3 & High & 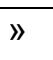 & Gaussmf $[3,397 ; 80]$ \\
\hline \multirow[t]{4}{*}{$\mathrm{D}$} & \multirow[t]{4}{*}{$0,51-0,78$} & D1 & \multicolumn{2}{|c|}{ Bad desirability } & $\begin{array}{l}\text { Trimf } \quad[0,54 ; 0,63 ; \\
0,72]\end{array}$ \\
\hline & & D2 & Satisfactory & 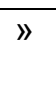 & $\begin{array}{l}\text { Trimf }[0,62 ; 0,71 ; \\
0,8]\end{array}$ \\
\hline & & D3 & Good & 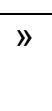 & $\begin{array}{rll}\text { Trimf } & {[0,65 ;} & 0,74 ; \\
0,83] & \end{array}$ \\
\hline & & D4 & Very good & " & $\begin{array}{c}\text { Trimf } \quad[0,69 ; \quad 0,78 ; \\
0,87]\end{array}$ \\
\hline
\end{tabular}


Figure 2-6 shows the Fuzzy Inference System Editor; Editor of membership functions for terms of variable D; the Surface of Fuzzy Inference and the Rule Editor as applied to the desirability of a complex quality indicator entomophage Habrobracon hebetor; Fuzzy System Viewer.

In tabl. 4 the knowledge base of the fuzzy system for assessing the desirability of the complex indicator of the quality of the entomophage Habrobracon hebetor is given; for each row of tabl. 4 corresponds to one rule: if T = "Low temperature" and W = "Low humidity", then D = "Bad desirability."

\section{Knowledge base}

\begin{tabular}{|c|c|c|c|}
\hline № & T & W & D \\
\hline 1 & T1 & W1 & D1 \\
\hline 2 & T1 & W2 & D1 \\
\hline 3 & T1 & W3 & D1 \\
\hline 4 & T2 & W1 & D2 \\
\hline 5 & T2 & W2 & D2 \\
\hline 6 & T2 & W3 & D2 \\
\hline 7 & T2 & W1 & D3 \\
\hline 8 & T2 & W2 & D4 \\
\hline 9 & T2 & W3 & D4 \\
\hline 10 & T3 & W1 & D3 \\
\hline 11 & T3 & W2 & D4 \\
\hline 12 & T3 & W3 & D4 \\
\hline
\end{tabular}

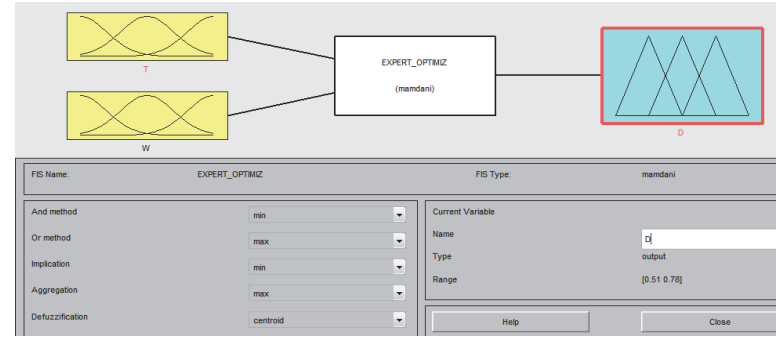

Fig. 2 Fuzzy Inference System Editor

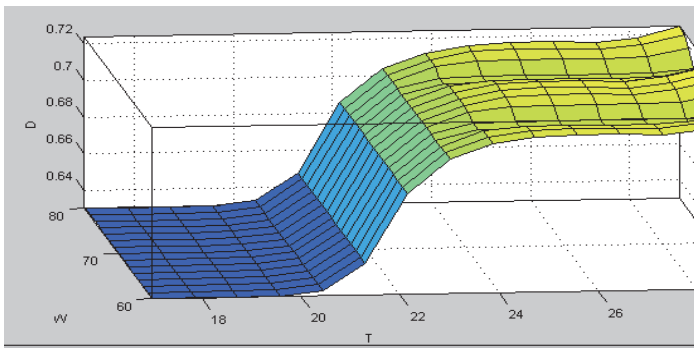

Fig. 4 Surface of Fuzzy Inference $D=f(T, W)$

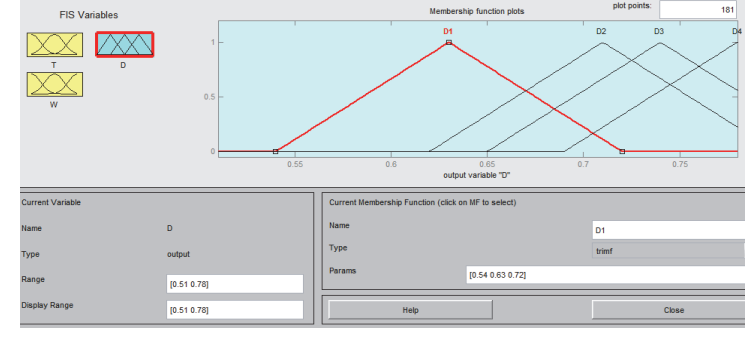

Fig. 3 Editor of membership functions for terms of variable $D$

1. If ( $T$ is $T 1$ ) and $(W$ is $W 1)$ then (D is D1) (1) 2. If (T is $T 1$ ) and $(W$ is $W 2$ ) then (D is D1) (1)

3. If (T is $T 1$ ) and $(W$ is $W 3$ ) then (D is D1) (1)

4. If (T is $T 2$ ) and $(W$ is $W 1$ ) then (D is D2) (1)

5 . If ( $T$ is $T 2$ ) and $(W$ is $W 2$ ) then (D is D2) (1)

6. If ( $T$ is $T 2$ ) and $(W$ is $W 3$ ) then (D is D2) (1)

7. If (T is T2) and (W is W1) then (D is D3) (1)

8. If (T is T2) and ( $W$ is $W 2$ ) then (D is D4) (1)

9. If ( $T$ is $T 2$ ) and $(W$ is $W 3$ ) then (D is D4) (1)

10. If (T is $\left.T^{3}\right)$ and $(W$ is $W 1$ ) then (D is $D 3$ ) (1)

11. If $(T$ is $T 3$ ) and $(W$ is $W 2$ ) then (D is $D 4$ ) (1)

12. If ( $T$ is $T 3$ ) and $(W$ is $W / 3$ ) then (D is $D 4$ ) (1)

Fig. 5 Rule Editor as applied to the desirability of a complex quality indicator entomophage Habrobracon hebetor 


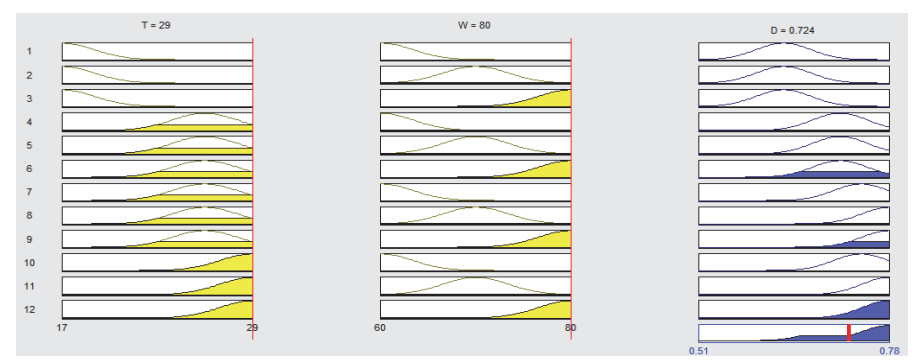

In tabl. 5 the fuzzy estimation of the desirability of the complex index of the quality of entomophage Habrobracon hebetor is given.

5. Fuzzy estimation of the desirability of the complex index of the quality of entomophage Habrobracon hebetor

\begin{tabular}{|l|c|c|c|}
\hline $\begin{array}{l}\text { Air } \\
\text { temperature, } \\
{ }^{\circ} \mathrm{C}\end{array}$ & $\begin{array}{l}\text { Air } \\
\text { relative } \\
\text { humidity, } \\
\%\end{array}$ & $\begin{array}{c}\text { Experimental } \\
\text { desirability } D^{e}\end{array}$ & $\begin{array}{c}\text { Fuzzy } \\
\text { desirability } D^{n}\end{array}$ \\
\hline 17 & 60 & 0,56 & 0,63 \\
\hline 17 & 70 & 0,51 & 0,63 \\
\hline 17 & 80 & 0,56 & 0,63 \\
\hline 20 & 60 & 0,58 & 0,63 \\
\hline 20 & 70 & 0,63 & 0,63 \\
\hline 20 & 80 & 0,62 & 0,63 \\
\hline 23 & 60 & 0,69 & 0,71 \\
\hline 23 & 70 & 0,71 & 0,71 \\
\hline 23 & 80 & 0,71 & 0,71 \\
\hline 26 & 60 & 0,74 & 0,72 \\
\hline 26 & 70 & 0,77 & 0,72 \\
\hline 26 & 80 & 0,78 & 0,72 \\
\hline 29 & 60 & 0,72 & 0,72 \\
\hline 29 & 70 & 0,78 & 0,72 \\
\hline 29 & 80 & 0,78 & 0,72 \\
\hline
\end{tabular}


According to the fuzzy conclusion, the desirability of 0,72 of the complex indicator of the quality of the entomophage Habrobracon hebetor $(1,13)$ corresponds to the assessment of "very good" at air temperature $(25-29){ }^{\circ} \mathrm{C}$ and relative humidity $(60-80) \%$.

The average error of approximation between the experimental and fuzzy desirability of a complex index of entomophage Habrobracon hebetor quality is calculated by formula (4) [17] and is 6,7\%:

$$
\bar{A}=\frac{1}{n} \sum\left|\frac{D^{e}-D^{H}}{D^{e}}\right| \cdot 100 \%,
$$

where $n$ - the number of measurements; $D^{e}$ - experimental desirability of $\mathrm{K} ; D^{H}$ - fuzzy desirability of $\mathrm{K}$.

The average error of approximation does not exceed 8-10\% [17].

\section{Conclusions}

An algorithm for optimizing the production of entomophages by the criterion of quality based on the theory of fuzzy logic is developed - entomological products with a "very good" quality index correspond to such microclimate parameters: air temperature (26-29) ${ }^{\circ} \mathrm{C}$ and relative humidity $(70-80) \%$. These parameters of the microclimate can be used in the formation of appropriate control strategies for the corresponding automation system.

\section{Bibliography}

1. Belyakova NA. Production of entomophages for greenhouse plant growing. Protection and plant quarantine. - 2013. - Vol. 5. - P. 9-12.

2. Markina T.Yu. Changes in the structural parameters of silkworm populations BOMBYX MORI L. (LEPIDOPTERA, BOMBYCIDAE) in the optimization of cultivation. Bulletin of Kharkiv National Agrarian University, series biology. - 2009. - Vol. 1 (16). - P. 99-105.

3. Molchanova E.D., Sheikina E.B., Gorodetsky S.A. Optimization of fodder for growing a mill moth. Scientific-practical Center of the NAS of Belarus for agriculture. Collection of scientific works "Protection of plants." - 2015. - Issue. 39. - P. 191 - 196.

4. Belousov Yu.V, Sapozhnikova M.M., Anisimova N.M. The Influence of the kind of food imago on the demographic characteristics of the Chrysoperla Carnea. Bulletin of Agrarian Science of the Southern Region. - Odessa, 2012. - Issue. 12-13. - P. 156-163.

5. Krasavina L.P. Optimization of the breeding process Aphidius kolemani. Protection and plant quarantine. - 2009. - Vol. 1. - P. 39 - 42.

6. Markina T. Yu. Structural features of artificial populations of insects as a basis of their functional stability.The Kharkov Entomological Society Gazette 2007 (2008). - Vol. XV. - Issue 1-2. - P. 197-200.

7. Bachinskaya Ya.A., Zlotin A.Z., Markina T.Yu. Optimization of spatial structures of cultures of LYMANTRIA DISPAR L. (LEPIDOPTERA: LYMANTRIIDAE )and SITOTROGA CEREALELLA OLIV. (LEPIDOPTERA: GELECHIIDAE). The Kharkov Entomological Society Gazette 2003 (2004). Vol. XI. Issue 1-2. - P. 197-201.

8. Lysenko V.F., Chernova I.S. Formation of requirements to the energy efficient quality management systems entomophages. Materials of International scientific-practical conference "Biotechnology Systems of production and application of biologistics of agriculture "(October 3-7, 2016). - Information bulletin IOBS EPRS. - Issue 49. - Odessa, 2016. - P. 155-160.

9. Marteijn R.C.L., Jurrius O.; Dhont J.; Gooijer C.D.de; Tramper J.; Martens D.E. Optimization of a feed medium for fed-batch culture of insect cells using a genetic algorithm. Biotechnology and Bioengineering. - 2003. - Vol. 81. - Issue 3. - P. 269-278.

10. Belyakova N.A. Features of modern technology mass breeding of entomophages. Plant protection and quarantine, 2010. - Vol. 8. - P. 18-20. 
11. Bulk breeding entomophage Habrobracon hebetor. Temporary technological regulations TTP00495929-021: 2013 / ETI "Biotechnics" NAAS. - Odessa - 2013. - 51 p.

12. Azgal'dov G.G., Raykhman E.P. About qualimetry. M., Publishing House of Standards, 1973. $172 \mathrm{p}$.

13. Lysenko V.P., Miroshnik V.O., Landel T.I. Optimization of tomato growing in a greenhouse using the Harrington desire function. Automation of technological and business processes. - 2015. - Vol. 7 . Issue. 4. - P. 33-39.

14. Bulgakova I.N., Morozov A.N. Use of the "desirability function for the formalization of a complex indicator of the competitiveness of an industrial enterprise. Bulletin of the VSU. Series Economics and Management, 2009. - Issue 2. - P. 54-56.

15. Suleimenov B.A. Methods of creating intelligent and hybrid process control systems. Engineering Education and Science in the 21st Century: Problems and Perspectives: Proceedings of the International Forum dedicated to the 80th anniversary of KazNTU named after K.I. Satpayev. - 2014.- Vol. II. - P. 290295.

16. Mazorchuk M.S., Simonova K.A., Grekov L.D. Application of methods and models of fuzzy logic for modeling economic processes . Sistemi obrobki informatsii. - 2007. - Issue. 9 (67). - P.159-162.

17. Shalabanov A.K., Roganov D.A. Econometrics. Teaching-methodical manual. Kazan: Academy of Management "TISBI". - 2008. - 203 p. 